\title{
Surveillance of work related and occupational respiratory disease-SWORD
}

The burden borne by society in the management of respiratory disease is a large one, and in no comparable range of illnesses is the influence of the environment so much greater than that of genetic factors. From the recognition of the causes of tuberculosis and pneumonia to the appreciation of the influences of cigarette smoking on health, physicians interested in lung disease have been closely associated with important opportunities to ameliorate adverse environmental effects and so prevent disease. So far most important advances in the prevention of lung disease have stemmed from epidemiological research. For long we have been familiar with statistical information on tuberculosis and lung cancer. We have watched with satisfaction the decline of the former disease in the West and have debated the value of further preventive measures in the light of knowledge of the statistics. We continue to view with concern worldwide trends in lung cancer mortality, and plan strategies to counter the commercial activities of the cigarette industry on the basis of this information. Information about prevalence and incidence is the sword with which we attack the dragon of disease.

Since the days of Ramazzini, physicians have been interested in work as a potential cause of ill health. The Industrial Revolution caused an awakening of professional consciousness of the malign influences of unbridled factory enterprise on the less fortunate, and among the epidemics of cholera and typhoid physicians became aware also of pneumoconiosis. The turn of the century brought the exploitation of asbestos, followed by the burgeoning of metallurgical, chemical, and plastics industries. Behind all this industrial activity lay an increasingly productive and efficient agricultural and food enterprise; all are potential causes of lung disease in workers. Until quite recently, however, we have had little information on the relative importance of workplace factors in the causation of lung disease. We have been aware that a wide range of lung diseases may be caused by exposure to harmful substances at work, but there has been a general feeling that these conditions are uncommon and, this being so, that preventive measures may not be a worthwhile priority. A further consequence of ignorance about the frequency of occupational lung diseases is likely to be a tendency not to suspect them, and therefore to miss the diagnosis. This in turn may have two consequences: the patient continues to be exposed to the harmful environment, and the opportunity to prevent disease in others is missed.

Awareness of our ignorance of the size of the problem led members of the British Thoracic Society to discuss means of setting up a reporting scheme for work related and occupational respiratory diseases, an endeavour that has led to the formation of SWORD, whose first report has just been published. ${ }^{1}$ Most British chest physicians and many occupational physicians now carry yellow cards in their briefcases, recording details of any new patients they see with occupational lung disease and returning the cards monthly or quarterly to the project coordinator. In return, they receive a monthly statement of the numbers of cases reported, a short "case of the month" report, and a quarterly analysis of results.

The SWORD reporting scheme protects the confidentiality of those making reports as well as that of the patients reported. In its first year of operation, 1989, 2101 new cases of occupational lung disease were reported by the more than 700 participating doctors. ${ }^{1}$ Twenty six per cent of those were asthma, 13\% mesothelioma, and $13 \%$ pneumoconiosis. Some $40 \%$ of the cases of occupational asthma were ascribed to causes other than those on the schedule of prescribed diseases. The report attempts to estimate the rates of disease in different industrial sectors, an estimate dependent on knowledge of the numbers employed and therefore likely to be close to the truth only in the case of diseases that occur as a result of current exposure, such as asthma. Annual rates per 100000 employed of around 60 new cases of occupational asthma for spray painters, 40 for chemical and plastics process workers, and a similar number for bakers have been derived. The report also comments on the reliability of the information so far recorded and concludes that, at least for asthma, the true rates are likely to be perhaps three times the recorded rates.

Chest physicians will find much to interest them in this first report. So perhaps will lawyers, who have recently evinced a strong curiosity about the risks that people in certain jobs who have pleural plaques will subsequently develop mesothelioma. Here the annual rates need to be treated with care because cases of mesothelioma occurring now result from exposure many years ago, when the relevant workforce was usually much larger and the level of exposure to asbestos much higher.

Physicians participating in the scheme will be aware of some of the results for 1990, whose value was enhanced by greater participation of occupational physicians and by some adjustment and clarification of diagnostic categories. This allowed, for example, the recording of 285 cases of inhalation accident, $14 \%$ of the total diseases recorded. The SWORD scheme is now running smoothly and will shortly provide not only a useful means of tracking trends and monitoring the efficacy of preventive measures but also an important base of information for research into the causes and effects of occupational lung diseases.

SWORD is indebted to Dr Sarah Meredith and her colleagues at the London Chest Hospital, and to the Health and Safety Executive for its support.

ANTHONY SEATON

Department of Environmental and Occupational Medicine,

University Medical School,

Aberdeen AB9 $2 Z D$

Reprint requests to Professor Seaton

1 Meredith SK, Taylor VM, McDonald JC. Occupational respiratory disease in the United Kingdom, 1989. Br J Ind Med 1991;48:292-8. 